CARVALHO, W. A. de. A biblioteca pública e as ações de incentivo à leitura: abordagem realizada em uma escola municipal de Córrego Fundo-MG

\title{
A BIBLIOTECA PÚBLICA E AS AÇÕES DE INCENTIVO À LEITURA: ABORDAGEM REALIZADA EM UMA ESCOLA MUNICIPAL DE CÓRREGO FUNDO-MG
}

\author{
Wanessa Antunes de Carvalho \\ Bibliotecária. Pós-graduada em Biblioteconomia e Gestão de Projetos
}

Recebido em: 04/08/2014

Aprovado em: 28/10/2014

\begin{abstract}
RESUMO
O presente artigo aborda a finalidade da biblioteca pública, descrevendo sua missão e funções. Narra a intervenção realizada em uma escola municipal de ensino fundamental na cidade de Córrego Fundo - MG, através da realização de um museu, o Museu de Clássicos Infantis. Objetivando incentivar o hábito de leitura dos contos clássicos adormecidos na biblioteca e a formação moral da criança, realizou-se a montagem de um stand para as histórias escolhidas, com a representação de objetos contidos nos contos. Por meio do incentivo à leitura dos contos clássicos a biblioteca observou uma procura maior pelas obras representadas no museu. E observou-se que os ensinamentos contidos nas obras foram absorvidos por cada criança de maneira única, respeitando o desenvolvimento cognitivo de cada idade e série.
\end{abstract}

Palavras-chave: Biblioteca pública. Hábito de leitura. Clássicos infantis.

\section{PUBLIC LIBRARY AND THE SHARES TO PROMOTE READING: APPROACH HELD ON A MUNICIPAL SCHOOL OF CORRÉGO FUNDO-MG}

\begin{abstract}
This article discusses the purpose of the public library, describing its mission and functions. It reports the intervention performed in a municipal elementary school in the city of Córrego Fundo-MG, by creating a museum, the Museum of Children's Classics. Aiming to encourage the habit of reading the classic tales that were asleep in the library and improve the moral education of the child. It was produced a stand for the chosen, with the representation of objects contained in fairy tales. By encouraging the reading of classic tales, the library noted an increased demand represented by works in the museum. It was observe that each child absorbed the teaching contained in the works in a unique way, respecting the cognitive development of each age and grade.
\end{abstract}

Keywords: Public Library. Reading habit. Children's classics. 
CARVALHO, W. A. de. A biblioteca pública e as ações de incentivo à leitura: abordagem realizada em uma escola municipal de Córrego Fundo-MG

\section{INTRODUÇÃO}

A biblioteca pública em tempos atuais deve ser vista não só como ambiente educacional, mas sim de lazer cultural, onde suas funções compreendam o incentivo à leitura e à formação do cidadão.

O presente trabalho teve como objetivo retomar a leitura dos contos clássicos pelos alunos de uma escola municipal de ensino fundamental da cidade de Córrego Fundo-MG, por meio de ações proativas realizadas pela biblioteca pública, além de proporcionar uma reflexão sobre a moral educativa contida nos clássicos escolhidos.

Assim objetiva-se responder à seguinte indagação: porque não utilizar a biblioteca pública como ponte de resgate literário dos clássicos infantis realizando atividades lúdicas com os alunos de escolas municipais?

\section{BIBLIOTECA PÚBLICA: FUNÇÕES E CONCEITOS}

Numa visão tradicionalista uma biblioteca é um local onde se guardam livros, ou melhor, onde se mantém coleções com informações diversas em formatos diferentes. Milanesi (1983, p. 93) define a biblioteca de forma ideológica quando afirma que "uma biblioteca deve ser um local de encontro e discussão, [...] onde é possível aproximar-se do conhecimento registrado e onde se discute criticamente esse conhecimento". ${ }^{1}$

As bibliotecas públicas são instituições socioculturais que disponibilizam informações a uma determinada comunidade. "O conceito de biblioteca pública baseiase na igualdade de acesso para todos, sem restrição de idade, raça, sexo, status social, etc. e na disponibilização à comunidade de todo tipo de conhecimento." (BIBLIOTECA..., 2000, p. 17). ${ }^{2}$

A biblioteca pública é aquela que tem por finalidade servir a massa, é um braço da educação a disposição do povo podendo ser considerada como complemento, uma extensão da escola. Ainda sobre isso Nogueira (1986, p. 220) comenta:

[...] o papel da biblioteca pública é ambivalente, exercendo '... não só a função de favorecer a reprodução das relações sociais estabelecidas, mas

\footnotetext{
${ }^{1}$ MILANESI, Luis. Biblioteca. Cotia: Ateliê Editorial, 2002.

${ }^{2}$ BIBLIOTECA Pública: princípios e diretrizes. Rio de Janeiro: Fundação Biblioteca Nacional, 2000.
} 
CARVALHO, W. A. de. A biblioteca pública e as ações de incentivo à leitura: abordagem realizada em uma escola municipal de Córrego Fundo-MG

também um papel de instrumento auxiliar de edificação de uma nova composição social. (NOGUEIRA, 1986, p. 220). ${ }^{3}$

As bibliotecas públicas tiveram sua origem na antiguidade, há cerca de 5 mil anos na cidade de Nipur, onde foi localizado um acervo de tábulas de argila. Desde então passaram por evoluções significativas, que resultaram na ressignificação de seu conceito.

A ideia de uma biblioteca pública a serviço de todos nasceu na Inglaterra, e ganhou impulso com a Revolução Industrial. Esse período trouxe mudanças significativas nas formas de trabalho o que, consequentemente, exigia do povo mais informações e qualificações. Essa colocação fica evidenciada por Nogueira (1986, p. 223) quando afirma:

Tendo por alavanca a Revolução Industrial, que exigia qualificação mais apropriada da força de trabalho e visando manter o novo modo de produção, impõe-se a necessidade do ensino formal como meio de aperfeiçoamento individual e de desenvolvimento nacional, Neste contexto, a biblioteca pública apresenta-se como mais um artificio de garantia da democratização do saber (NOGUEIRA, 1986, p. 223).

Com o passar dos anos o amadurecimento da biblioteca pública foi tomado por dimensões mais concretas e seu papel e função foram definidos com mais propriedade em várias partes do mundo. Almeida (2013, p. 249) afirma que:

o ano de 1850 é normalmente determinado por vários autores como a data
aproximada do surgimento da biblioteca pública tanto nos Estados Unidos
como na Inglaterra. Seria essa a data mundial do nascimento da biblioteca
pública, dentro dos moldes como é entendida hoje, ou seja, uma instituição
mantida quase que integralmente pelo estado e voltada para o atendimento,
sem distinção, de toda a população (ALMEIDA, 2013, p. 249).

Como instituição voltada à aquisição e disseminação de informações, as funções da biblioteca pública estão indiscutivelmente ligadas à leitura, pesquisa e cultura e divididas da seguinte forma:

Função recreativa ou de lazer: a biblioteca pública deve ser capaz de oferecer entretenimento através da leitura, possibilitando às pessoas leitura em qualquer horário que desejar;

\footnotetext{
${ }^{3}$ BIBLIOTECA Pública: princípios e diretrizes. Rio de Janeiro: Fundação Biblioteca Nacional, 2000.
} 
CARVALHO, W. A. de. A biblioteca pública e as ações de incentivo à leitura: abordagem realizada em uma escola municipal de Córrego Fundo-MG

Função cultural: surgiu no início do século XX com a democratização da informação, repassando conhecimento, valorizando determinadas formas de expressões artísticas, música, dança, cinema etc.

Função informacional: a biblioteca pública é responsável por atuar como ponte na busca de soluções para problemas da vida cotidiana e para isso conta com informações úteis, ou seja, informações que não são encontradas em documentos que dão respostas às necessidades do dia-adia;

Função educativa: cabe a esta função atenção especial, tendo em vista que a biblioteca pública completa os conhecimentos adquiridos na escola, enriquecendo amplamente a possibilidade do acesso ao conteúdo em maior quantidade e algumas vezes até na qualidade.

Ainda sobre a função educativa cabe ressaltar a inserção das tecnologias de informação que, proporcionam à biblioteca pública a melhoria de seus serviços, oportunizando a democratização ao acesso à informação por meio da internet e suas ferramentas. No texto da Fundação Biblioteca Nacional fica claro que é:

[...] evidente o papel da biblioteca pública no Brasil de hoje - como a mais democrática instituição de caráter cultural e educacional a qual sem dúvida alguma, tem a vocação nata para exercer um papel social de grande relevância na inserção da sociedade brasileira na sociedade da informação (BERNARDINO; SUAIDEN; CUEVAS-CERVERÁ, 2013 apud BIBLIOTECA PÚBLICA, 2013, p. 7). ${ }^{4}$

Percebemos então que apesar de diferenciadas, suas funções se completam e se aperfeiçoam com objetivo de democratizar o acesso à informação através dos tempos, adequando-se as necessidades, peculiaridades e tecnologias vigentes, oferecendo um suporte amplo à educação em seus múltiplos saberes.

Sobre isso Bernardino; Suaiden e Cuevas-Cerverá (2013, p. 14) constatam que:

Os aspectos relacionados ai acesso á informação e a evidenciação da função social, cultural, e educativa da biblioteca pública se faz presente em vários objetivos e missão, que por sua vez trazem em seu bojo ações de alfabetização informacional entre outras. Neste sentido a biblioteca pública assume a função de mediadora da informação e da aprendizagem e a competência informacional, assim como a tecnologia, se converte em

\footnotetext{
${ }^{4}$ BERNARDINO, Maria Cleide Rodrigues; SUAIDEN, Emir Jose; CUEVAS-CERVERÓ, Aurora. A biblioteca pública e sua função educativa na sociedade da informação. RACIn, João Pessoa, v. 1, n. 2, p. 5-20, jul./dez. 2013.
} 
CARVALHO, W. A. de. A biblioteca pública e as ações de incentivo à leitura: abordagem realizada em uma escola municipal de Córrego Fundo-MG

elemento chave para o processo de aprendizagem informacional BERNARDINO; SUAIDEN; CUEVAS-CERVERÁ, 2013, p. 14, apud BIBLIOTECA PÚBLICA, 2013).

\section{BIBLIOTECA PÚBLICA E ESCOLA}

A escola é, na maioria das vezes, o primeiro contato que a criança tem com a educação formal. Crianças que têm contato desde cedo com obras literárias compreendem melhor ao outro e a si própria, desenvolve melhor sua criatividade, emoção, razão e sua criticidade. Isso permite que a criança perceba a realidade e o mundo em que vive de maneira a desenvolver simultaneamente capacidades e habilidades para viver melhor. Nesse período de aprendizagem a criança tem aguçados seus anseios de conhecer o mundo, sua curiosidade e o discernimento do certo e do errado. Nesse contexto, o papel da biblioteca escolar como elemento integrador é fundamental no ambiente escolar e para o desenvolvimento das crianças. Principalmente no que se refere aos hábitos de leitura, ao conhecimento de diversos suportes e tipos textuais e aos aspectos críticos em relação à sociedade na qual está inserida.

Os objetivos da biblioteca escolar não fogem à regra geral que direciona os serviços de qualquer biblioteca seja ela escolar, pública, especializada ou universitária, a disseminação de informações está presente em todas. Sendo assim, a biblioteca pública caminha lado a lado com a biblioteca escolar, completando os conhecimentos adquiridos no ambiente escolar. Sobre isso Oliveira e Zen (2007, p. 5) comentam:

\footnotetext{
As bibliotecas como instituições que oferecem informações em forma de livros e de outros suportes, enquanto as demais instituições culturais referemse a outros tipos de acervo, especializados em diferentes formas de acesso á arte e a cultura. Trata-se, portanto, de organizações que, embora diferentes se completam, uma vez que todas se constituem em locais onde o consumo, a criação e a ação cultural manifestam-se em plenitude. No Brasil, onde o número de instituiçõos culturais especializadas é reduzido, as bibliotecas tem sua responsabilidade cultural aumentada ao despertar esse papel social importante de desenvolver formação cultural do país (OLIVEIRA; ZEN, 2007 , p. 5). ${ }^{5}$
}

\footnotetext{
${ }^{5}$ OLIVEIRA, Débora Costa; ZEN, Ana Maria Dalla. Ação cultural em bibliotecas escolares da rede pública de Porto Alegre. Disponível em: < http://www.lume.ufrgs.br/bitstream/handle/10183/10234/000323648.pdf?sequence=1>. Acesso em: 10 maio 2013. 
CARVALHO, W. A. de. A biblioteca pública e as ações de incentivo à leitura: abordagem realizada em uma escola municipal de Córrego Fundo-MG

Atualmente, inovações como livros confeccionados com materiais diversos, acolchoados, plumas, dispositivos sonoros, encadernações diferentes, papéis que brilham, somados às tecnologias como áudio livros, e-books, etc., são atrativos que chamam a atenção dos leitores para o aspecto físico do livro, despertando o desejo de ler, sugestionando que se a aparência do livro é agradável seu conteúdo também o é. A literatura estrangeira é um fator de peso no gosto literário dos jovens leitores, uma vez que ela apresenta temas atraentes para as crianças, uma extensa variedade de romances com vampiros, mitologia, bruxos, enfim, o chamado realismo fantástico. Esse tipo de romance está cada vez mais disponível no mercado livresco, o que acaba deixando para trás as velhas histórias que a vovó contava.

Partindo desse pensamento, buscou-se realizar uma abordagem significativa na Escola Municipal Teresa Maria de Faria Vaz, que concentra a maior porcentagem de usuários da Biblioteca Pública Maria José Arantes. As ações realizadas voltaram-se para estimular o hábito de leitura e incentivar uma leitura diferenciada dos clássicos infantis, pois eles não tem sido procurados pelos alunos da escola.

Tal constatação resultou na seguinte indagação: porque não utilizar a biblioteca pública como ponte para um resgate literário dos clássicos infantis realizando atividades lúdicas com os alunos de uma Escola Municipal?

O bibliotecário, ao gerar situações estimuladoras e eficazes, é capaz de realizar atividades lúdicas com a utilização de ferramentas de aprendizagem e desenvolvimento buscando estimular o interesse do aluno pela atividade de leitura. Assim, poderá proporcionar níveis diferentes de experiência pessoal e social na criança, ajudando-o a construir suas descobertas, a desenvolver e enriquecer sua personalidade. No incentivo ao hábito de leitura, o papel do bibliotecário se configura na criação de espaços e de atividades lúdicas, no oferecimento de textos diferenciados e, na mediação da aprendizagem ao fazer com que a criança adquira valores e conhecimentos.

\section{OS CONTOS CLÁSSICOS E A EDUCAÇÃ̃o}

A literatura infantil surgiu por volta do século XVII, período em que houve a reorganização do ensino e da fundação do sistema educacional burguês. Antes desta data as crianças eram vistas como adultos, participavam da vida adulta em igualdade com os adultos, sem distinção de atividades.

Conexão ci.: r. cient. UNIFOR-MG, Formiga, v. 9, n. 2, p. 48-62, jul./dez. 2014 
CARVALHO, W. A. de. A biblioteca pública e as ações de incentivo à leitura: abordagem realizada em uma escola municipal de Córrego Fundo-MG

\begin{abstract}
Esta faixa etária não era percebida como um tempo diferente, nem o mundo da criança como espaço separado. Pequenos e grandes compartilhavam dos mesmos eventos, porém nenhum laço amoroso especial os aproximava. A nova valorização da infância gerou uma nova união familiar, mas igualmente os meios de controle do desenvolvimento intelectual da criança e manipulação de suas emoções. Literatura infantil e escola, inventada a primeira e reformada a segunda, são convocadas para cumprir essa missão (ZIBERMAN, 1998, p. 13). ${ }^{6}$
\end{abstract}

Há relatos de que os primeiros livros infantis foram escritos por professores pedagogos com objetivos educacionais, confirmando assim a aproximação da escola com a literatura infantil.

Não havendo livros, nem histórias dirigidas especificamente a elas, não existiria nada que pudesse ser chamado de literatura infantil. Por este viés na origem da literatura infantil estariam os livros publicados a partir dessa época, preparados especialmente para crianças com intuito pedagógico, utilizados como instrumento de apoio ao ensino (AZEVEDO, 2001, p. 1).

Dado o pontapé inicial com a criação dos livros infantis, a literatura infantil foi ganhando nuances significativas com objetivo de ensinar conteúdos curriculares, como o trabalho de Orbis Sensualium Pictus (1658) de Comenius, obra criada com intuito de ensinar latim através de gravuras. A utilização da literatura infantil ganhou dimensões imensuráveis como apoio na formação da personalidade infantil por meio da leitura dos contos clássicos; ou como forma de ensinar valores morais e éticos; ou com a biblioterapia que utiliza obras literárias para a resolução de conflitos pessoais. Cademartori (1994, p. 23) afirma que a literatura infantil se configura não só como instrumento de formação conceitual, mas também de emancipação da manipulação da sociedade.

A literatura infantil, os contos clássicos de fadas, príncipes e bruxas devem ocupar lugar de destaque na formação das crianças. Ouvindo histórias elas se colocam no lugar dos personagens o que, consequentemente, as leva à resolução de seus conflitos internos de modo irrefletido. Por exemplo, uma criança que vive um conflito com sua madrasta ao ouvir a história da Branca de Neve inconscientemente se identifica com o enredo do conto. Ela transfere o problema vivido pela personagem para o momento que está vivendo aplicando-o na sua situação de uma forma mais suave. Assim, a criança

\footnotetext{
${ }^{6}$ ZIBERMAN, Regina. A literatura infantil na escola. São Paulo: Global, 1995.
} 
CARVALHO, W. A. de. A biblioteca pública e as ações de incentivo à leitura: abordagem realizada em uma escola municipal de Córrego Fundo-MG

consegue compreender seu conflito, buscando sozinha a solução para o problema vivido.

Os valores dos clássicos da literatura infantil muitas vezes passam despercebidos pelos educadores que os utilizam apenas com objetivo de entretenimento, não percebendo a riqueza de ensinamentos contida nos contos.

\begin{abstract}
A fantasia dos contos de fadas é fundamental para o desenvolvimento da criança. Há significados mais profundos nos contos de fadas que se contam na infância do que na verdade que a vida adulta ensina. É por meio dos contos infantis que a criança desenvolve seus sentimentos, emoções e aprende a lidar com essas sensações (RESSUREIÇÃO, 2005, p. 19). ${ }^{7}$
\end{abstract}

Há uma estreita relação entre os contos clássicos e a educação, pois o primeiro prioriza a formação psicossocial da criança, trabalhando valores morais e éticos através do imaginário infantil. Já a segunda, objetiva formar o cidadão pleno, consciente de seus direitos e deveres, utilizando as disciplinas como forma de condensar a realidade em conteúdos curriculares.

Escola e biblioteca pública são instituições ligadas ao ensino e à formação do cidadão, por isso, bibliotecários, professores, pais, diretores e demais profissionais ligados à educação escolar devem trabalhar em ações conjuntas para, não somente incentivar o hábito de leitura, mas também para não deixar que os contos clássicos caiam no esquecimento.

\title{
5 METODOLOGIA
}

Trabalhar o resgate dos clássicos infantis através da ludicidade não implica necessariamente em trabalhar com "jogos". Neste trabalho buscou-se outra forma de dimensionar o interesse das crianças para a literatura infantil adormecida, uma forma inédita e criativa: a representação das histórias escolhidas por meio de um museu, o Museu dos Clássicos Infantis.

\footnotetext{
${ }^{7}$ RESSUREIÇÃO, Juliana Boeira da. A importância dos contos de fadas no desenvolvimento da imaginação. Rio Grande do Sul. Disponível em: < http://www.facos.edu.br/old/galeria/ 129102010020851.pdf>. Acesso em: 10 maio 2013.
} 
CARVALHO, W. A. de. A biblioteca pública e as ações de incentivo à leitura: abordagem realizada em uma escola municipal de Córrego Fundo-MG

Essa pesquisa classifica-se como descritiva, quanto aos seus objetivos. A pesquisa descritiva é definida por Costa e Costa $(2001 \text {, p. } 15)^{8}$ como a mais tradicional das pesquisas. Ela descreve características de uma determinada população ou um determinado fenômeno.

Em relação ao seu delineamento este trabalho representa um estudo de caso, que se caracteriza como um estudo limitado a uma ou poucas unidades, que podem ser uma pessoa, uma família, um produto, uma instituição, uma comunidade ou mesmo um país. É uma pesquisa detalhista e profunda.

Possui abordagem qualitativa que é descrita da seguinte forma por Costa e Costa (2001, p. 12):

\begin{abstract}
A [pesquisa] qualitativa se preocupa com uma realidade que não pode ser quantificada. Ela trabalha com o subjetivo dos sujeitos (crenças, valores, atitudes, etc.) Essa abordagem também pode trabalhar com dados, porém o tratamento não deve envolver estatística avançada.
\end{abstract}

Classifica-se também como pesquisa bibliográfica realizada em livros, revistas, jornais. A pesquisa bibliográfica é básica para qualquer tipo de pesquisa, mas também pode esgotar-se em si mesma. (COSTA; COSTA, 2001, p. 15).

O local escolhido para a realização do trabalho foi uma escola municipal de ensino fundamental localizada na cidade de Córrego Fundo-MG. A escola conta com uma equipe de 22 professoras, 2 coordenadoras pedagógicas, 1 diretora, 1 bibliotecária, 1 auxiliar de secretaria, 3 auxiliares de serviços gerais, 2 auxiliares de educação, 1 instrutor de informática, 5 cantineiras. A população do estudo foram os 400 alunos da escola.

O trabalho realizado objetivou levar o conto aos alunos oportunizando às crianças um mundo mais criativo e de conhecimento imaginário. A pesquisa foi realizada durante um dia todo, compreendendo os turnos matutino e vespertino da instituição.

As ações realizadas visavam desenvolver nas crianças o seu lado cognitivo, imaginário, simbólico e representativo, levando cada uma delas a uma percepção diferente do que era visto.

\footnotetext{
${ }^{8}$ COSTA, Marco Antonio F. da; COSTA, Maria de Fátima Barrozo da. Metodologia da pesquisa: conceitos e técnicas. Rio de Janeiro: Intertexto, 2001.
} 
CARVALHO, W. A. de. A biblioteca pública e as ações de incentivo à leitura: abordagem realizada em uma escola municipal de Córrego Fundo-MG

Após analisar quais eram os clássicos infantis que estavam em desuso na biblioteca pública, por meio da observação diária da estatística de empréstimos, foram selecionadas 10 histórias para serem representadas em um museu. Observou-se também a moral incutida nessas histórias, sua forma de transformar a realidade em fantasia de uma forma quase imperceptível aos pequenos. Então, foram recriadas no museu algumas situações de fantasia vistas nos livros. Os contos escolhidos foram: Chapeuzinho vermelho, Branca de Neve, Pinóquio, Cinderela, Os três porquinhos, Peter Pan, João e Maria, A bonequinha preta, João e o pé de feijão e O gato de botas.

Assim, cada história teve um espaço na quadra da escola que foi dividida em 10 estandes para expor alguns objetos representativos dos contos.

Ao visitarem os estandes, os alunos observavam os objetos e ouviam a explicação da história e da moral nela contida. Ao terminarem a visitação no museu, eles eram direcionados a uma sala onde as histórias eram vistas em forma de desenho animado. E por fim, as crianças podiam desfrutar das oficinas de desenho e pintura de rosto. No final da visita cada criança recebia um kit com 10 lembrancinhas referentes a cada um dos contos: chaveiros, adesivos, marcadores de livros, mini livrinhos e ponteiras de lápis.

O primeiro estande visitado foi o da Cinderela: a forma como uma camponesa é tratada pela sua madrasta e suas irmãs foi retratada para as crianças. A pobre moça é obrigada a realizar trabalhos domésticos e a viver em condições precárias, enquanto suas irmãs tinham outro padrão de vida. Cinderela sofre, pois sabe que se seu pai estivesse vivo sua vida seria diferente. Mas, de repente, sua vida se transforma completamente: a carência que ela tinha deu lugar ao amor pelo príncipe.

O que dizer de duas crianças que dependem exclusivamente dos pais para tudo e se descobrem abandonados pelos pais? Assim se desenrola o conto de João e Maria: duas crianças que perdem seu porto seguro e são obrigadas a sobreviver da forma mais inusitada possível. Essa história contém mensagens importantes para a formação da criança, João e Maria que antes tinham um lar, comida e uma vida aparentemente normal, de repente são obrigados a lidar com a falta e o abandono.

O mito de que contar mentira faz crescer o nariz vem do conto do Pinóquio, que passa para a criança as consequências de se contar mentira, reforçando um valor moral e transmitindo-o de forma lúdica sem perder a essência. 
CARVALHO, W. A. de. A biblioteca pública e as ações de incentivo à leitura: abordagem realizada em uma escola municipal de Córrego Fundo-MG

A infância é um período caracterizado por desobediências, as crianças começam a desobedecer aos pais, aos professores, avós e a todos aqueles que estão ao seu redor. Esse problema pode ser minimizado com a ajuda do conto da Bonequinha Preta de Alaíde Lisboa. Nele a menina Mariazinha resolve ir dormir um pouco e pede para que sua bonequinha não suba na janela. Mas logo depois que Mariazinha cai no sono a bonequinha não se aguenta de curiosidade para ver o que está além da janela e acaba desobedecendo as ordens de sua dona, o que lhe traz sérias consequências. Esse conto ajuda a criança a compreender as consequências de seus atos. $\mathrm{O}$ mesmo acontece no conto de Chapeuzinho Vermelho, quando a mãe pede à filha que não converse com estranhos e não se distraia no caminho. As recomendações da mãe não foram atendidas, Chapeuzinho Vermelho encontra-se com o Lobo e conversa com ele, desobedecendo a sua mãe.

Com a história da Branca de Neve podem ser trabalhados os sentimentos de inveja e raiva. A madrasta da Branca de Neve desenvolve um sentimento de inveja pela beleza da moça e faz com que ela passe por situações de perigo. Mas como nos contos de fadas o bem sempre vence o mal, a madrasta teve seu feitiço voltado contra ela. Esse conto pode ajudar na assimilação dos conceitos do bem, do mal, inveja e raiva pelas crianças de maneira agradável e inofensiva.

$\mathrm{Na}$ narrativa dos Três Porquinhos um ponto forte que foi trabalhado com as crianças é que todo esforço traz um resultado. Os três irmãos tinham mentalidades diferentes, todos tinham o mesmo objetivo, porém a forma como cumpriam suas atividades era diferente. Heitor e Cícero queriam construir suas casas apenas pensando no momento, ou seja, não pensavam que a casa seria um bem que lhes serviria futuramente de abrigo. Eles utilizavam seu tempo com brincadeiras e descanso. Já o porquinho Prático, que apresentava uma maturidade superior a dos seus irmãos, pensou logo em construir uma casa resistente que o abrigasse das ameaças do mundo exterior. Transpondo a realidade dos porquinhos para as crianças, pode-se trabalhar a ideia de que tomar um tempo maior para executar uma tarefa da maneira correta, deixando as brincadeiras para depois, é a melhor solução para quem busca um bom resultado.

Para as crianças, fadas, duendes, bruxas e outros personagens dos clássicos infantis vão além da imaginação, pois estão sempre em seus pensamentos. Qual garotinha nunca pensou em ser uma fada? Ou qual menino nunca quis voar como Peter Pan? Na Terra do Nunca a fantasia impera, as crianças nunca crescem, as brincadeiras Conexão ci.: r. cient. UNIFOR-MG, Formiga, v. 9, n. 2, p. 48-62, jul./dez. 2014 
CARVALHO, W. A. de. A biblioteca pública e as ações de incentivo à leitura: abordagem realizada em uma escola municipal de Córrego Fundo-MG

são eternas, mas no mundo real as crianças vivenciam situações diferentes das contadas nos conto do Peter Pan. O que foi extraído desse conto e transmitido para as crianças é que muitas vezes queremos sair de casa, em busca de algo melhor, em busca de um lugar onde não há regras, horários e atividades a serem cumpridas. Principalmente as crianças de pais separados, que acreditam que a casa do outro (pai ou mãe) é melhor do que aquela onde está vivendo. Porém, quando as crianças se deparam com ambientes e rotinas diferentes, reconhecem que o melhor é voltar pra casa como fez Wendy, que voltou para o seu lar, na história de Peter Pan.

$\mathrm{O}$ conto do João e o Pé de Feijão possui uma moral mais difícil para o entendimento das crianças, principalmente para as crianças menores. João recebeu ordens de sua mãe para vender a vaca, pois a família precisava de dinheiro. Mas João não fez o que a mãe lhe ordenara e optou por tomar sua própria decisão. $\mathrm{O}$ menino enxergou outra possibilidade de utilizar o dinheiro da venda da vaca, além da que a mãe lhe mostrou. Ele acreditou que os feijões mágicos poderiam mudar o curso da sua vida e de sua família. Assim, assumiu a responsabilidade pelas consequências do seu ato e seguiu a vontade de seu coração. Transmitir para as crianças a moral desse conto é complicado, porque as crianças podem entender que João foi errado ao desobedecer as ordens de sua mãe. Mas, ser forte o suficiente para tomar uma decisão que poderia afetar toda a história de sua família é algo surpreendente vindo de uma criança. Acreditar no impossível, apostar na luz no fim do túnel são atitudes inesperadas que podem gerar bons resultados.

Por fim, o último conto escolhido para ser representado no Museu dos Clássicos

Infantis foi o Gato de Botas. É a história de um moleiro que momentos antes de sua morte resolve dividir seus bens entre seus filhos. Ao filho mais velho deixou um moinho, ao do meio um burro de carga e ao mais novo um gato. $\mathrm{O}$ filho mais novo achou que o pai tinha sido injusto ao repartir seus bens, afinal que valor teria um gato? Mas assim que ouviu o gato falar, mudou sua relação com o bichinho e os dois passaram a ser grandes amigos. Fica evidente nesse conto o valor de uma amizade, pois os bens e a herança podem acabar, mas uma verdadeira amizade nunca morre.

\section{ANÁLISE DOS DADOS}


CARVALHO, W. A. de. A biblioteca pública e as ações de incentivo à leitura: abordagem realizada em uma escola municipal de Córrego Fundo-MG

Os instrumentos para alcançar os resultados da pesquisa foram o diário de campo e um questionário. O diário de campo, instrumento que permitiu uma melhor compreensão das atividades, foi preenchido pela bibliotecária responsável pelo evento, observando as ações e emoções das crianças ao final de cada período trabalhado.

O questionário foi aplicado um dia após o evento, em horário de intervalo das professoras. Distribuído pela pesquisadora e recolhido no mesmo dia, ele foi respondido pelas professoras, que identificaram em seus alunos o impacto das atividades do Museu dos Clássicos Infantis.

Para atingir os objetivos do estudo os dados interpretados no questionário e no diário de campo foram analisados. Ambos possuíam alternativas que descreviam as emoções das crianças antes e depois da visita ao museu, identificando possíveis reações dos pequenos em consequência da apreensão da moral contida em cada história. Observou-se que a criança transportou para sua realidade e rotina as ações, valores e condutas que ficaram no seu inconsciente após a representação das histórias.

A Biblioteca Pública Maria José Arantes contava com 23 sócios frequentadores da biblioteca. Após a realização do evento na escola esse número passou para 95 sócios, sendo 78 crianças e alunos da escola e, 17 que são pais destes alunos.

\section{CONSIDERAÇÕES FINAIS}

Tendo em vista a questão colocada inicialmente, e após a interpretação dos dados do questionário e do diário de campo, foi possível chegar a algumas conclusões.

Em relação ao incentivo à leitura dos contos clássicos, notou-se na biblioteca pública, uma procura maior pelas obras representadas no museu. Por meio do manuseio dos livros, as crianças buscavam identificar os objetos representados no museu e isso levou a um aumento da procura pelos clássicos infantis. Na biblioteca, os livros foram dispostos de maneira diferente da habitual, colocados em evidência nos expositores coloridos.

No que diz respeito à moral educativa, notou-se que os ensinamentos de cada obra foram absorvidos pelas crianças de maneira única, respeitando o desenvolvimento cognitivo de cada idade e de cada série.

É importante ressaltar que, após a realização do museu, a chegada de novos sócios fez com que os antigos sócios e frequentadores tivessem outra visão da biblioteca Conexão ci.: r. cient. UNIFOR-MG, Formiga, v. 9, n. 2, p. 48-62, jul./dez. 2014 
CARVALHO, W. A. de. A biblioteca pública e as ações de incentivo à leitura: abordagem realizada em uma escola municipal de Córrego Fundo-MG

e percebessem que a função da biblioteca pública não é só emprestar livros, ou auxiliar na realização de pesquisas, ela é capaz de desenvolver de forma plena suas funções e ainda auxiliar o cidadão em seu desenvolvimento cultural e social.

\section{REFERÊNCIAS}

AZEVEDO, R. Literatura infantil: origens, visões da infância e certos traços populares. Presença Pedagógica, Belo Horizonte, n. 27, 2001.

BERNARDINO, M. C. R.; SUAIDEN, E. J.; CUEVAS-CERVERÓ, A. A biblioteca pública e sua função educativa na sociedade da informação. RACIn, João Pessoa, v. 1, n. 2, p. 5-20, jul./dez. 2013.

COSTA, M. A. F. da; COSTA, M. de F. B. da. Metodologia da pesquisa: conceitos e técnicas. Rio de Janeiro: Intertexto, 2001.

BERTELHEIM, B. A psicanálise dos contos de fadas. 14. ed. Rio de Janeiro: Paz e Terra, 1980.

BIBLIOTECA Pública: princípios e diretrizes. Rio de janeiro: Fundação Biblioteca Nacional, 2000.

CADEMARTORI, L. O que é literatura infantil. São Paulo: Brasiliense, 1984.

CARVALHO, D. S. de C. A importância da ludicidade na educação infantil. 1999. 40 f. Trabalho de Conclusão de Curso (Graduação em Pedagogia)-Centro Universitário de Formiga-UNIFOR-MG, Formiga, 1999.

CUNHA, M. V. da. O papel social do bibliotecário. Encontros Bibli: revista eletrônica de Biblioteconomia e Ciência da Informação, Florianópolis, n. 15, 2003.

GIL, A. C. Métodos e técnicas de pesquisa social. São Paulo: Atlas, 1999.

MANIFESTO DA IFLA/UNESCO sobre bibliotecas públicas. 1994. Disponível em: <http://snbp.bn.br/manifesto-da-unesco-sobre-bibliotecas-publicas/>. Acesso em: 20 abr. 2013.

MILANESI, L. Biblioteca. Cotia: Ateliê Editorial, 2002.

OLIVEIRA, D. V. de F.; SABINI, M. A.; VASCONCELOS, M. A. O conto de fadas na educação infantil. In: CONGRESSO NACIONAL DE EDUCAÇÃO, 25., 2012, Jataí. Anais... Jataí: UFG, 2012.

OLIVEIRA, D. C.; ZEN, A. M. D. Ação cultural em bibliotecas escolares da rede pública de Porto Alegre. Disponível em: < http://www.lume.ufrgs.br/bitstream/ handle/10183/10234/000323648.pdf? sequence=1>. Acesso em: 10 maio 2013. 
CARVALHO, W. A. de. A biblioteca pública e as ações de incentivo à leitura: abordagem realizada em uma escola municipal de Córrego Fundo-MG

RESSUREIÇÃO, J. B. da. A importância dos contos de fadas no desenvolvimento da imaginação. Rio Grande do Sul. Disponível em: <http://www.facos.edu.br/old/ galeria/129102010020851.pdf>. Acesso em: 10 maio 2013.

VIEIRA, I. M. de C. O papel dos contos de fadas na construção do imaginário infantil. Revista Criança, Brasília, jan. 2005.

ZIBERMAN, R. A literatura infantil na escola. São Paulo: Global, 1995. 